\title{
Divergência em Barrela, de Plínio Marcos
}

\author{
Lucio Allemand Branco ${ }^{1}$
}

RESUMO: Este trabalho aborda o conceito sociológico de divergência na peça inaugural de Plínio Marcos, Barrela, ambientada numa cela de prisão, na qual seus personagens convivem sob as regras de um código interno que reflete, em muito, aquele que os levou ao confinamento. Preliminarmente, analisamos as possíveis convergências entre as dramaturgias de Plínio e Nelson Rodrigues do ponto de vista dos temas e da linguagem.

ABSTRACT: This paper deals with the sociological concept of divergence in the first play by Plínio Marcos, Barrela, which takes place in a prison cell in which the characters live under the rules of an internal code that clearly reflects the one that brought them to confinement. Initially, we focus on the possible convergences between Plínio and Nelson Rodrigues' play-writings from the point of view of themes and language.

PALAVRAS-CHAVE: Prisão; Divergência; Estigma; Subjetividade.

KEYWORDS: Prison; Divergence; Stigma; Subjectivity.

Barrela, peça inaugural da obra de Plínio Marcos, foi escrita em 1958, ano que marca emblematicamente a produção dramatúrgica no Brasil. O Teatro de Arena vivia seu auge, com o êxito da encenação de Eles não usam black-tie, drama proletário então inédito no Brasil (em conjunto com montagens anteriores, de cunho político-social semelhante), que já sinalizava quais os contornos que o grupo fundado por José Renato e outros que o tomariam como modelo, assumiriam a partir de então. Dentro dos termos de uma periodização histórica oficial, talvez se possa dizer que o teatro brasileiro ingressava no terceiro estágio da sua modernização, sendo, por convenção, os dois anteriores: a consagrada montagem original de Vestido de Noiva, de Nelson

\footnotetext{
${ }^{1}$ Lucio Allemand Branco, doutorando em Literatura Comparada pela Universidade do Estado do Rio de Janeiro (UERJ), A santa absolvição do crime: violência, revolta $e$ religiosidade nas dramaturgias de Jean Genet e Plinio Marcos. Contato: lucioallemandbranco@yahoo.com.br.
} 
Rodrigues, em 1943, sob a direção do polonês Zbigniew Ziembinski; e a fundação do Teatro Brasileiro de Comédia (TBC), do italiano Franco Zampari, em 1948. (Ver PRADO, 2001)

Nesse contexto, após a experiência cênica nacional ter completado sua maioridade, é que surge acenando solitária a obra de Plínio Marcos. Em contraponto aos dogmas do dominante teatro politico em voga, o enredo de Barrela é centrado no conflito de individualidades (nada há nele, por exemplo, que guarde afinidade com o conceito de "peça de tese". A cartilha do engajamento ideológico no ambiente teatral pregava a denúncia das mazelas sociais e, tendo a ação dramática invariavelmente como pano de fundo a luta de classes, o conflito se desenrolava esquematicamente em termos de oprimidos contra opressores - o operariado, o campesinato, eram finalmente alçados à condição de protagonistas. Essa tendência iria se acentuar nos anos seguintes, com a adoção e peculiar adaptação de recursos tomados de empréstimo às teorias brechtianas, como o "efeito do distanciamento", visando despertar a consciência política do espectador.) Coerentemente com toda sua produção posterior, esta "peça em um ato" (MARCOS, 2002) já traz uma série de elementos marcadamente plinianos que, como se costuma apontar, traem uma inegável descendência da linhagem inaugurada por Nelson Rodrigues (que afirmava ser o autor de Barrela uma espécie de seu sucessor).

Pode-se afirmar que isso é consenso nas análises feitas sobre a produção dramatúrgica brasileira. Nelson Rodrigues, com o ciclo das suas "tragédias cariocas" (como o crítico Sábato Magaldi convencionou denominar oito do total de dezessete de suas peças [MAGALDI in RODRIGUES, 1981-1990]), passou a realçar a cor local da vida carioca, com seus tipos folclóricos, maneirismos e modalidades de comportamento que remetiam a uma estrutura cultural singular. $\mathrm{O}$ coloquial subitamente permeava o texto teatral, operando, com isso, uma sensivel alteração não só na linguagem verbal dos personagens aproximando-os assim das formas de expressão restritas ao cotidiano, e nunca antes presentes no "espaço nobre" de um palco - mas também 
na linguagem cênica. Tanto o Teatro de Arena como Plínio Marcos esmeraram-se na criação de um universo dramático popular que comportasse uma linguagem que pretendia traduzir aquilo que poderiamos chamar de sua "essência". Os menos privilegiados passaram a ter vez (e voz) graças a uma remodelação das técnicas interpretativas usuais, numa empresa a qual o Arena se lançou num esforço coletivo e programático, e que o texto pliniano ensejava de modo suigeneris.

Há, ainda, uma identificação de fundo de Plínio com o ideário humanista rodriguiano, influência verificável, em parte, do ponto de vista espiritual (simultaneamente nos sentidos filosófico e místico), que ganha forma dramática em enredos que, invariavelmente, encenam a necessidade de redenção do indivíduo, condenado a uma existência trevosa, à sombra de provações e sacrificios que supliciam a carne e a alma nas situações construídas. O modelo de conflito entre a natureza trágica da condição humana (já por si mesma conflituosa) e o seu contraponto vital, a busca incessante de luz por parte dos seus personagens, é uma constante não só na dramaturgia de ambos mas, genericamente, nas suas respectivas obras literárias. Inescapavelmente, o confesso viés dostoiévskiano do universo ficcional de Nelson Rodrigues constitui, aqui, uma fonte primordial.

\section{Barrela}

Barrela inicia com seis personagens trancafiados numa cela. Atendem pelos epitetos de: Bereco, Portuga, Tirica, Bahia, Fumaça e Louco. É noite, e todos dormem em cena. Subitamente, Portuga acorda, aos gritos, após o recorrente pesadelo que lhe traz à memória o crime que o levou à prisão: o assassinato de sua esposa, que, pelo que tudo indica, decorreu de um flagrante de adultério. Esse acontecimento detona o conflito sobre o qual se alicerça toda a ação da peça: a partir dele, instaura-se, através da ameaça permanente da curra, um processo crescente de luta pelo poder no interior daquele espaço mínimo. 
A brutalidade do cárcere é uma atmosfera quase irrespirável, inescapável; romper com ela significa deslegitimar os mecanismos alternativos de controle que se estabelecem para a manutenção da ordem instituída pelos detentos. As regras que compõem esse regulamento interno integram uma reprodução microcósmica, particularizada, da estrutura sociocultural maior. Externamente, esta fornece o modelo pelo qual um repertório sui generis de regras nãoescritas, porém cumpridas à risca, faz-se valer dentro do "xadrez". Pautados nesses padrões, desvelam-se valores que, apesar da sua natureza original um tanto imprecisa, difusa, ganham, neste espaço, o estatuto de lei inviolável, cuja inobservância é inapelavelmente punida. Um exemplo claro de um valor instituído no meio prisional e que constitui o motivo central do enredo de Barrela, é a função atribuída à inversão dos papéis sexuais que se verifica no ato da curra. A posse sexual à força é o meio pelo qual o elemento ativo da relação afirma sua autoridade através do expediente mais brutal de humilhação alheia a que se pode recorrer - uma espécie de rito que tem por fim alocar determinados indivíduos nos espaços a eles reservados na escala hierárquica do cárcere. Predomina então o conceito de que a exacerbação da virilidade é o valor premente para a necessária aquisição ou manutenção do poder. Para o código moral dominante que vigora na estrutura sociocultural maior que não prevê, legitima ou naturaliza relações de tipo homossexual, eis uma inversão prevista, legítima e naturalizada na rotina das prisões que nada mais é do que um fenômeno universal da cultura carcerária. Pode-se dizer que, no repertório de práticas de afirmação do poder próprias ao meio, dentre as quais se inclui a curra, quando não há explicitamente disputa pela conquista desse poder, almeja-se, no minimo, fazer-se respeitar ali.

O "xerife" da cela, Bereco, que legitima sua ascendência sobre os demais por meio da força física, é contrário qualquer à violência sexual, e, portanto, toda vez que ela pareça iminente, basta sua intervenção para que sua prática fique em suspenso. Ele é a autoridade inconteste naquele ambiente, sua palavra tem peso de lei para o estabelecimento 
da ordem local - também é ele, por exemplo, quem determina quando se pode fumar maconha, uma das ocupações mais requisitadas pelos detentos. Bereco faz crer que é constantemente solicitado pelas circunstâncias a decretar seus veredictos:

Aqui o cão sou eu. Quem não fizer o que eu mandar, se estrepa. A não ser que tenha mais briga que eu. Mas corto o saco se alguém aqui me escora. (Pausa.) Então, é como eu digo. Não quero putaria nessa joça. Maconha só roda quando eu deixar. Assim é que é. (MARCOS, 2003, ps. 46-47)

Entende-se que a autoridade do "xerife" sobre os demais se dá conforme uma delegação não-oficial, apenas reconhecida pelo código interno dos presos, espécie de “instituição total" (GOFFMAN, 2007), conforme formulação de Erving Goffman, a qual se define como uma auto gerência estabelecida à parte da pena da lei que preside a vida social comum, e que funciona enquanto alegoria deste regulamento, em parte, autossuficiente. Mas sua existência pode acabar por prestar um auxílio involuntário à autoridade legal, na medida em que é ela uma espécie de sua reprodução, mesmo que precária. Ou seja, também pode funcionar como anteparo à eclosão de rebeliões, desde que haja contrariedade às ordens do "xerife", e este se veja na necessidade de intervir no andamento das turbulências internas do cotidiano prisional. A instituição policial figura na cena (literal e simbolicamente) tanto de forma um tanto indireta, verbal, através da inevitável menção que dela fazem os personagens aprisionados, como de forma dramaticamente concreta, por meio da breve aparição, ao final da peça, de um carcereiro e de dois guardas. Entregue a sua própria sorte, a população carcerária é vítima da conivência da sociedade para com a calculada negligência por parte do aparelho policial com relação às condições de vida reservadas a ela, no cumprimento de suas penas, que, como sabemos, dá-se, simultaneamente, sob a vigência do seu regulamento alternativo. Excluído que é da vida social, esse contingente humano tem a sua relativa autonomia vigiada a uma distância determinada por um 
controle institucional que se exerce somente com vistas a que não se ultrapasse certo limite, o qual é demarcado pelo poder disciplinar oficialmente constituído. A rebelião, por exemplo, é um fenômeno de ruptura da ordem legal; ela constitui uma exceção nociva ao funcionamento regular do sistema de segurança, e afeta diretamente o sentimento de indiferença da estrutura social externa quanto ao destino dessa população indesejada, usualmente designada pela expressão "depósito humano", denotativa do abandono a que é condenada. Assim, recai sobre o dispositivo policial a expectativa de se reprimir com urgência - sob pena de ficar ameaçado seriamente o estado de estabilidade social - as consequências da autonomia parcial das "leis" que regem exclusivamente esse universo.

À luz do posicionamento crítico assumido em geral por Plínio Marcos, depreendemos que ele concebe a estrutura social como organizada, mantida e sempre fortalecida por valores de uma determinada estrutura cultural que estimula a competitividade entre os indivíduos. Fenômeno este resultante de um esforço de aprimoramento das estratégias sociais - orientadas, em principio, por normas institucionais (MERTON, 1970) abalizadas pelo conjunto da sociedade que visam o êxito final das aspirações desses mesmos indivíduos. A dissidência para com a expectativa normatizada de comportamento social reflete aquilo que, em sociologia, define-se como "comportamento desviante" (VELHO, 1985) (interessa-nos, aqui, essencialmente, o caso da exteriorização das psiques criminosas no dia a dia do convívio forçado do confinamento). No mérito específico da categoria dos meios institucionais, nota-se uma distinção dual quanto à adoção do gênero de norma para a realização final dos objetivos estipulados culturalmente. Há as normas institucionais e as normas técnicas: ambas a orientar as ações sociais dos individuos. (MERTON, 1970)

As primeiras constituem um tipo explicitamente referido a valores consagrados, considerados legítimos, de dada cultura. Repercutem positivamente no seio de um grupo social que as toma por fator de estruturação, ordenação e organização do sistema. Almejando sempre o 
atingimento dos objetivos culturais, esse gênero de norma se constitui pelo caráter dos expedientes formalmente aceitos. Estes são garantidos por uma concepção moral prévia que exclui práticas tidas como ilícitas. Ao sistema penitenciário, por suposição da sua legitimidade institucional, fica reservada a função de exigir e guardar a observância a essas normas. Sua atuação num presídio, por exemplo, centrar-se-ia, em tese, na exigência de que os internos primem pelo mesmo padrão.

Já as normas técnicas são o produto da índole pessoal, remetem aos valores alternativos de cada indivíduo, priorizando exclusivamente o aspecto da conveniência do meio de alcance do resultado imediato. São elas, em principio, uma resposta pessoal e intransferivel (na sua condição de estratégia) do indivíduo isolado à demanda do êxito social. Ajusta-se, nessa conceituação, o perfil das tendências marginais, cuja realização através do crime é um objetivo traçado em termos pragmáticos, algo que se dá sem grandes considerações de ordem moral. Escrúpulos não podem existir para o livre curso das atividades ilegais, pois, afinal de contas, a figura do fora da lei é consciente do caráter da sua opção de vida e, por conseguinte, de sua identidade social. Ocorre então o fenômeno de interiorização, que não é outra coisa que o processo que expõe a relação que o objeto do estigma (o fora da lei) tem com o próprio estigma. E segundo o sociólogo norte-americano Erving Goffman, estigmatização é "a deterioração da identidade do indivíduo a partir de uma característica (física ou comportamental.)" (GOFFMAN, 1975, p. 31) Podemos entender a interiorização como

o conceito que se sustenta sobre os desviantes como pessoas "imorais", "turbulentas", "perigosas" etc, permeia todo o sistema e desemboca afinal na representação que eles próprios se assumem sobre si mesmos (GOLDWASSER, 1985, p. 30)

No meio prisional, a divergência na esfera individual representa a imputação de um processo de estigmatização contra o indivíduo que cumpre pena e que, não raro ou eventualmente, manifesta seu inconformismo contra isso. (O estigma da criminalidade é tão aderente 
que, até mesmo quem é de fato inocente, pode ser preso e ficar condenado a não poder se defender: - "Vim parar aqui por engano" [MARCOS, 2003, p. 32], é o que, em determinada altura, alega Bahia.) É a partir dessa premissa teórica que qualquer análise de desvio e divergência, ou outra categoria correlata, deve se desenvolver. Entendese que a construção da identidade divergente dos personagens de Barrela se fundamenta na sublimação singular de uma tendência comportamental que é comum a todo o universo ficcional pliniano, mas que, nesta peça, por ter como cenário o cárcere, figura com uma intensidade ainda maior. Afinal, a clausura do seu cenário determina outro código de relações interpessoais, porque se trata de uma situação dramática aparentemente sem saída. A ausência de um horizonte mínimo que seja (tal como na ilusão cultivada pelo personagem Tonho, de Dois perdidos numa noite suja, para quem um par de sapatos novos poderia torná-lo socialmente apresentável com vistas a obter um emprego e, por conseguinte, como sugere o sub-texto místicocompassivo da peça, redimi-lo desta "noite suja” e despertá-lo para a luz de um dia promissor. [MARCOS, 2003]) é o que faz o roteiro de Barrela ser de uma claustrofobia ainda maior que outras obras dramáticas de Plínio - nela, seus personagens sofrem uma dupla condenação. Vejamos isso...

À luz do conceito de divergência, em Barrela, entrevemos uma possivel articulação entre os dois paradigmas regulamentais em cena: o código oficial da instituição de segurança e o código não-oficial dos prisioneiros. Cada qual compõe uma totalidade una, coesa, e prestando contas somente aos seus mecanismos internos de funcionamento. Porém, também há a possibilidade de um embate entre seus limites, em que se estabelece uma dinâmica que opõe frontalmente seus respectivos dispositivos legais e ilegais, sob o ponto de vista tanto da norma institucional como do código informal intra prisional. Afinal, a noção de ilícito (na qual cabe o conceito de divergência) é prevista tanto por um como pelo outro. 
$\mathrm{Na}$ cadeia, as normas institucionais são compostas, originalmente, pelo regulamento jurídico-legal que estabelece, em princípio, o cumprimento de suas regras, via a ação da polícia. As possibilidades de infração penal são do conhecimento de todo o corpo carcerário, e a veleidade - por assim dizer - "atmosférica” da sua incorrência permanece sob a vigilância permanente do poder disciplinar. (FOUCAULT, 2007) Há um parentesco inequívoco entre esse código institucional formalmente legítimo e aquele informalmente estipulado pelos detentos, o qual só ganha a sua legitimidade graças a um acordo consensual não escrito de reconhecimento, entre os detentos, da autoridade reguladora que, via de regra, é encarnada na figura do "xerife". Neste último código, o "desvio" coletivo é quase uma impossibilidade, pois o seu rigor se mostra invariavelmente implacável. O que não é difícil de compreender, já que a sua vigência se dá entre quatro paredes afastadas do olhar público. Assim, pode-se concluir que o regulamento não oficial dos presos é capaz de uma maior eficácia prática, pois conta com uma aplicabilidade estrita e incontornável: seu peso de lei se verifica evidentemente na experiência diária do cárcere.

As normas técnicas, segundo a reflexão de Robert Merton (MERTON, 1970), são de uma outra natureza. Na sua transposição à presente análise, tanto podem ser avalizadas pelos presos como pela guarda prisional, na sua busca comum por alcançar ganhos individuais, como foi referido. Situadas fora do sistema oficial, ou seja, pertencentes a um código consuetudinário particular, essas normas são interpretadas, por princípio, como patrimônio exclusivo das inclinações comportamentais dos presidiários, mas, basta uma muito breve incursão no universo penitenciário para constatar que, amiúde, não é exatamente assim que as coisas transcorrem. Contrárias ao equilíbrio disciplinar, tais normas são fatores geradores de instabilidade e perturbação, em vários níveis da complexa rede de relações desse meio. Tanto numa possivel desobediência individual ao "xerife" da cela como numa rara "deposição" à força deste, mediante uma súbita revolta coletiva no "xadrez" (como também no caso de uma rebelião geral contra 
o sistema carcerário, como já foi mencionado); ou na inobservância de um policial a um superior hierárquico, ou, também, na paradoxal (ainda que recorrente) eventualidade do cumprimento de uma ordem por parte dos agentes penitenciários que resulta num massacre de presos, ferindo, assim, princípios legais, como os direitos humanos.

A proibição da curra pelo "xerife", além de expressar solidariedade para com o lado passivo e não consentido do ato, também dá testemunho da sua adesão à consagrada tese de que qualquer relação intima entre homens é, por princípio, condenável (“Tenho nojo de veado, um nojo do cacete. Raça nojenta!" [MARCOS, 2003, p. 47]), permanecendo essa como tabu, conforme a tábua de valores da cultura ocidental quanto à conduta moral associada ao sexo. Quando se instala a crise, através da ameaça do estupro de Portuga, Bereco, subitamente acordado pela "perturbação da ordem" na cela, decreta, com violência, a volta à normalidade, ali. Como Tirica foi o principal instigador da "punição" de Portuga (a quem chama provocativamente de "Cornélio"), acaba se convertendo no alvo preferencial deste, após serenarem os ânimos. Contribuindo no crescendo da intriga, Portuga afirma que, durante o rotineiro banho de sol dos presos, soube, pela boca do bandido Morcego, de um fato "comprometedor" do passado de Tirica: “Esse eu já estraçalhei. Foi lá no reformatório. Era comida do gango todo." (MARCOS, 2003, p. 38)

Após ser insistentemente instigado pelos companheiros de cela, Tirica confirma afinal a informação de Morcego. Porém, alega que:

os papacus estavam tudo lá, nas encolhas, só na boca de espera. Me ferraram. Que podia fazer? Precisava comer. Os mandarins não deixavam. Não deixam, não. [...] Vinha o rancho, já viu, eles encostavam como quem não quer nada e tchau, viravam tua marmita. $\mathrm{E}$ daí? $\mathrm{E}$ tu, ia reclamar pra quem? [...] É aguentar como pode. E foi o que eu fiz. Mas a barriga berra, meus camaradinhas. Berra! E toda a curriola sabe disso. E o frio, maruja? O frio arde pacas. E os mandarins estão aí mesmo, só pra tomar as cobertas do passarinho, na fisga. [...] Ou tu dá ou desce pro inferno, pintado de verde e amarelo. Tá bom? (MARCOS, 2003, p. 41) 
O relato só serve para os outros espicaçarem ainda mais Tirica. Provocado até um limite intolerável, ele escolhe seu principal desafeto, Portuga, para iniciar uma violenta luta corporal, que acaba por despertar novamente Bereco. Ele intervém mais uma vez, e com violência ainda maior. Quando é informado sobre o motivo da briga, declara, enfaticamente:

Não quero veadagem aqui, não. Tenho nojo de puto, já vou avisando. Vê lá, hein, Tirica. Se virar a mão aqui, te mato de pancada. [...] Aqui não quero fresco. [...] Papacu pra mim é puto também. [...] Se pego um veado aqui, esmago o desgraçado. (MARCOS, 2003, ps. 45-47)

Nenhum argumento parece demovê-lo dessa convicção, apesar do uso que faz da mesma ameaça de curra contra Louco (a reforçar seu caráter onipresente na cultura carcerária), quando este se demonstra demasiado entusiasmo com a possibilidade do estupro de Tirica. (No que se constitui, aparentemente, na única utilidade dramática do personagem, com sua lacônica e repetitiva fala: "Enraba, enraba!" [Ver MARCOS, 2003]. Já Bahia e Fumaça são os outros dois coadjuvantes que têm maior participação na intriga.) Mesmo sob o peso das advertências do "xerife", Tirica expõe mais um mandamento do código prisional: quando se jura alguém de morte, deve-se cumprir logo e sem vacilações o juramento - é o que pretende fazer com Portuga, quando ele vier a dormir. A tensão permanece, e cresce ainda mais a partir do momento em que Tirica começa a afiar o cabo de uma colher no chão. Imaginando o que está por acontecer, Portuga decide manter-se em estado de vigília. Subitamente, adentra na cela alguém visivelmente destoante do ambiente: o personagem Garoto, um rapaz de fino trato que ali foi parar em decorrência de uma briga num bar, e cujo pai não sabe do seu atual paradeiro, simplesmente pelo medo que o jovem tem de lhe relatar o ocorrido. Logo, Garoto é submetido a um ritual de iniciação da vida na prisão. Os bens que porta no momento são confiscados pelo "xerife": um maço de cigarros e "três contos". O que ficou retido na carceragem deve passar também para o nome de Bereco, 
como este determina. Isso é o suficiente para garantir a proteção do Garoto, portanto, a ordem agora é para manter o "bico calado", já que se deve voltar a dormir.

Mas Portuga passa a considerar a possibilidade de descarregar parte da tensão acumulada pela sequência de situações ditadas pelo confinamento sobre a figura do Garoto, presença inesperada e estranha ao elemento carcerário e, por isso mesmo, vítima em potencial das normas ("técnicas" [MERTON]) internas impostas pelos detentos. Logo, todos (à exceção de Bereco) se unem em torno de um único objetivo: a curra, ato que implica confrontar abertamente o mandato do "xerife" e operar, assim, uma inversão dos papéis predeterminados naquela conjuntura. Trata-se de um evento de acentuado caráter contra ideológico porque instaura a divergência num sistema teoricamente menos suscetível a fraturas, já que o seu rigor prevê punições irreversíveis, de acordo com este valor fundamental do código prisional: a estratificação hierárquica. Em nome desta, Bereco intervém em favor do jovem e acaba sendo ele, também, o alvo da inevitável reviravolta que vinha se delineando aos poucos no enredo da peça: um gradativo, tenso e velado processo de sublevação deflagrado pela reação geral ao pesadelo de Portuga. Tirica, dirigindo-se ao "xerife", decreta:

A gente é uma porrada. Dessa vez tu não vai pôr banca. Estamos de saco cheio das tuas broncas. Só tu que quer ter vez. Aqui ó, pra ti! A gente só pode bater caixa quando tu deixa. Só queimamos fumo quando tu tá de presa seca e os cambaus. Agora caiu do cavalo. Nós vamos enrabar esse garoto e, se tu folgar, não vai ter vez. [...] (Puxando a colher.) Vamos todo mundo junto. Quero ver qual é o veado que vai mijar fora do pinico. (MARCOS, 2003, p. 54)

Bereco se mostra condescendente e propõe, como solução para a crise, que se fume a reserva de maconha que ficou sob sua guarda. Esse improvisado "cachimbo da paz" é um expediente que visa serenar os ânimos e evitar o pior: o estupro do Garoto e a sua consequente perda de autoridade no "xadrez". Tirica, não negligenciando seu acerto 
de contas com Portuga, numa nítida inversão lógica, atribui ao seu desafeto o estigma da homossexualidade, na sua dimensão considerada mais comprometedora, a ausência de virilidade, por ele preferir fumar maconha a estuprar um homem. Como já dissemos, trata-se de um evidente paradoxo para com os valores de uma estrutura cultural que por uma questão ambivalente de definição, a priori, biológica, e princípio moral -, estipula, no plano discursivo, ser indubitavelmente homossexual também aquele que desempenha o papel ativo na relação com alguém do mesmo sexo. (A etimologia do termo já assim o determina, queremos crer.) Bereco é mesmo uma voz dissonante na cela ("Papacu pra mim é puto também" [MARCOS, 2003, p. 46]), identificada com o paradigma moral tradicional que determina a natureza dos costumes que compõem a conduta sexual dos indivíduos, nas sociedades ocidentais, podemos dizer. Tirica, acuado, passa a ver na curra do Garoto a necessidade de afirmação da sua masculinidade, condição e valor que, se postos em questão pelas normas desse regulamento interno, implica sofrer, inevitavelmente, o estigma reservado àquele que desempenha o papel passivo na relação entre iguais, independente das circunstâncias culturais, e para quem não há tolerância possível, em nenhum dos códigos de valor aqui mencionados. Ou seja, a recepção ao modo de "rito de passagem" a que estão prestes a submeter o Garoto pode consistir num ato coletivo divergente ao poder do "xerife", mas, em primeira instância, está plenamente integrada à ordem do dia, na prisão. Tirica dá sequência ao confronto:

TIRICA - São de porra nenhuma. Agora eu já vi quem é bicha. O Portuga foi o primeiro a sair fora. Claro, é brocha. Vai querer enrabar o Garoto pra quê?

FUMAÇA (Tirando o fumo e acendendo.) - Não reclama. Pega firme aqui, bichinha.

TIRICA - Eu, bicha? (Puxa o fumo.) Bicha é o Portuga, que não quis ferrar a menina aí.

(Todos estão puxando o fumo.)

TIRICA - Olha só o Garoto enxuto que vocês dispensaram.

(Todos riem.)

TIRICA - Depois, eu que sou fresco. Tá certo assim. Por mim, mandava o nabo nele. 
PORTUGA - Vai lá, então.

TIRICA - Sozinho na dá. Segura ele que tu vê se sou homem ou não.

PORTUGA - Chama o Morcego. Ele que sabe de ti.

(Todos riem.)

TIRICA - Não se escama. O Garoto está aí, a gente pode provar.

(MARCOS, 2003, ps. 54-55)

Após fumarem maconha - inclusive o Garoto, à força - a ação vai numa progressão na qual as provocações reciprocas de Tirica e Portuga culminam na curra do jovem como prova da tese de que, quem não falha no desempenho do papel ativo na "barrela" é de uma virilidade inconteste, e, por isso, é merecedor do respeito dos demais. (Curiosamente - talvez para não ver mais ameaçada sua liderança -, o "xerife" Bereco se torna cúmplice do estupro coletivo não realizando propriamente $\mathrm{o}$ ato [o que contrariaria os seus princípios], mas prestando auxílio a sua realização, ao fixar os calcanhares da vítima no chão, quando esta se encontra de bruços.) Como Tirica não conseguiu cumprir o que tanto alardeara, permanece como o alvo preferencial das ofensas dos companheiros de cela: verdade?

BAHIA - Quer dizer que o Morcego falou a

PORTUGA - Agora tivemos a prova. Eu fui lá e pimba! Mandei brasa. O Tirica, com toda a visagem, só fez brochar. Caiu a cara do puto.

FUMAÇA - Foi bom esse lance. Até o Louco se tratou. Pro Tirica não deu, é bicha mesmo.

TIRICA - Foi esse Portuga que ficou me gozando. Isso dá terra.

BAHIA - Com a gente não deu.

PORTUGA - Ninguém aqui é veado.

TIRICA - O Bereco também não foi.

FUMAÇA - Porque não quis. Agora tu, não. Tu quis pacas, deu até dó. Mas, que nada! Não enganou ninguém.

BAHIA - Nem vai enganar nunca mais.

BERECO - Pára de chorar, Garoto. Ninguém te machucou. (Pausa.) Pára, anda! Já mandei. acostuma.

BAHIA - Não chora não, menina, logo você

PORTUGA - Não vê o Tirica? Agora acabou a banca. Daqui pra frente vai ser menina. 
FUMAÇA - Sabe que quando o Portuga falou do papo do Morcego, eu pensei que o Tirica era gilete? Agora vi que nem isso o filho-da-puta é. (MARCOS, 2003, p. 57)

Mais uma vez, Bereco decreta que é hora de dormir, e, quando todos se vão acomodando, Tirica finalmente consuma aquilo que até então, era só ameaça: com a ponta afiada do cabo da colher, ele mata Portuga, numa explosão irreprimivel de ódio. Observando mais um mandamento interno das prisões, ninguém interfere. A realização do acerto de contas tem a seu favor a impassibilidade dos circunstantes, a caracterizar a autossuficiência imposta pelo "manual de sobrevivência" no cárcere, o que confirma o mudo e onipresente casuísmo as suas regras, e a correspondente eficácia prática da sua aplicação no dia a dia dos detentos. Cabe a estes, ao término de mais este evento usual de violência, avisar à autoridade legal o ocorrido, através dos sinais tradicionais de luto:

(Fumaça pega um pano preto e pendura na janelinha da porta. Todos, como que tomados, pegam suas canecas e começam a batê-las. Logo começa um barulho idêntico de fora de cena, como se fosse de outras celas. No auge do barulho, escuta-se o ferrolho correr. Todo o barulho para como por encanto. Entra o trio da guarda.)

GUARDA 1 - Todo mundo de nariz na parede. Anda! Seus filhos-da-puta! Não podiam esperar mais um pouco pra aprontar o salseiro? Mais dez minutos e era a rendição que ia resolver essa alteração... Filhos-da-puta!

GUARDA 2 - Apagaram um!

GUARDA 1 - Um a menos pra encher o saco. [...] Manda buscar a maca. (MARCOS, 2003, ps. 59-59)

A "lei do silêncio" se impõe para calar a delação, infração reputada como a mais grave na escala de desvios previstos pelo regulamento informal que vigora no "xadrez", e, para a qual, não existe perdão possível. Quando um dos guardas indaga o "xerife" sobre a identidade do assassino, a resposta não poderia ser outra: "Não sei. Eu estava dormindo." (MARCOS, 2003, p. 59) Atestando a parcial negligência do sistema penitenciário com relação às condições de vida sob o confinamento, o autor da pergunta, então, deduz e decide, ao 
flagrar Tirica com a sua arma improvisada: "Vamos arrastar esse pra solitária. Tem que ser alguém, né? Esse aí serve. Desce ele." (MARCOS, 2003, p. 59) Os guardas removem o corpo de Portuga, e, também, seu assassino, agora visivelmente perturbado pelo sucedido. Após um breve intervalo, eles voltam, mas tendo à frente, agora, o carcereiro, que anuncia: “José Cláudio Camargo.” (MARCOS, 2003, p. 59) O Garoto atende, revelando quem, de fato, é. Trata-se do único personagem, dentro do drama, verdadeiramente portador de uma identidade própria. Ao cumprir a formalidade de chamar o preso pelo seu nome completo, no anúncio de sua liberação, o carcereiro involuntariamente lhe confere uma subjetividade individualizada, impar, identificável segundo o padrão social, normatizado, formal. Os outros personagens se conhecem somente pelos apelidos os mais ordinários, e, em grande parte, atribuídos a eles a partir de um dado ínfimo que acaba por ganhar uma definição totalizante que, muito frequentemente, presta-se a ecoar o estigma. Não devemos aludir apenas à pouca relevância que o emprego do apelido comumente carrega (o sinônimo "vulgo" parece não querer dizer outra coisa). Aqui, nesta peça em um ato, sua significação tem maior alcance dentro do roteiro dramático compassivo pliniano porque realçam o caráter homogeneamente impessoal daqueles reféns de adversidades diárias, vítimas mais sintomáticas que são da crise dos valores aparentemente universais e consagrados que, por convenção, pertencem ao campo das virtudes humanas, no locus singular da cadeia. Os ocupantes originais do "xadrez" estavam relegados à condição aviltante de um assujeitamento resultante da circunstância do abandono desse segmento marginalizado pela estrutura social (a clássica indagação da prostituta Neusa Sueli, em Navalha na carne, “Poxa, será que sou gente?” [MARCOS, 2003, p. 164] serve aqui, como um justo emblema disso). A possibilidade de subjetivação singularizada no universo carcerário - na qual se incluem valores, atitudes, comportamentos etc, próprios do meio criminal e já previstos pelo seu respectivo regulamento interno - fica teoricamente restrita a um indivíduo estranho a esse universo que, no seu elemento original, 
parece ser portador de uma subjetividade tão assujeitada quanto a de seus algozes, pois seu comportamento sugere ser ele um membro enquadrado nos padrões vigentes de normalidade moldados pela estrutura social maior. A divergência é um fenômeno de subjetivação singularizada tanto pelo que se evidencia no estigma atribuído à figura do fora da lei, sempre à margem das atribuições do comportamento dito sociável - razão que levou aqueles seis primeiros personagens à cadeia quanto na visivel identidade divergente do Garoto na cela, um desvio, por si só, evidente e passivel de punição segundo os valores do modus vivendi local. Inevitavelmente, a permanência desse jovem em elemento tão hostil a sua condição estava fadada a ser suspensa pela intervenção da "normalidade" institucional, como a via necessária de afirmação, alocação e estratificação das instâncias hierárquicas da estrutura social. A resolução dos conflitos de Barrela tem uma peculiar aura de fatalidade trágica: o poder disciplinar pode até parecer que tarda, mas nunca falha. Sem figurar fisicamente na cena, até este momento, ele acaba por surgir apenas ao fechar das cortinas para provar que, mesmo, indiretamente, sempre esteve ali. O tom conclusivo, quase conformado, da fala que fecha a primeira peça de Plínio Marcos, já prenunciava, então, o sentido geral do seu projeto dramático, desvinculado das soluções ao gosto do projeto revolucionário da sua geração e tributário mesmo de um sentido geral de compaixão cristã, que não deixa de ecoar, involuntariamente ou não, o legado rodriguiano:

FUMAÇA - Eu queria me mandar.

(Pausa.)

BAHIA (Da janelinha da porta) - Já está amanhecendo.

(Pausa longa.)

BAHIA - Já estão servindo café no xadrez um.

(Pausa longa.)

BERECO - É... Mais um dia... (MARCOS, 2003, p.

\section{REFERÊNCIAS BIBLIOGRÁFICAS:}


ARISTÓTElES. Poética. São Paulo: Nova Cultural, 1999.

DURKHEIM, Émile. O suicídio. São Paulo: Martin Claret, 2003.

FOUCAULT, Michel. A ordem do discurso. São Paulo: Loyola, 1996. . Vigiar e punir. Rio de Janeiro: Vozes, 2007.

GOFFMAN, Erving. Desvio e comportamento desviante, estigma: notas sobre a manipulação da imagem deteriorada, Rio de Janeiro: Zahar, 1975.

- Manicômios, prisões e conventos. São Paulo, Perspectiva, 2007.

GOLDWASSER, Maria Júlia. "Cria fama e deita-te na cama: um estudo da estigmatização numa instituição total”. In: VELHO, Gilberto. Desvio e divergência, uma crítica da patologia social. Rio de Janeiro: Zahar, 1985.

MAGALDI, Sábato. Prefácios de Nelson Rodrigues: teatro completo. Quatro vols. Rio de Janeiro: Nova Fronteira, 1981-1990. - Moderna dramaturgia brasileira. São Paulo: Perspectiva, 1998.

MARCOS, Plínio. Melhor teatro. São Paulo: Global, 2002.

MENDES, Oswaldo. Bendito maldito: uma biografia de Plinio Marcos. São Paulo: Leya, 2009.

MERTON, Robert. Sociologia: teoria e estrutura. São Paulo: Mestre Jou, 1970. 
MIRANDA, Luciana Lobo. "Subjetividade: a (des)construção de um conceito" In: Subjetividade em questão: a infância como crítica da cultura. Rio de Janeiro: 7 Letras, 2000.

PEREIRA, Victor Hugo Adler. A musa carrancuda: teatro e poder no Estado Novo. Rio de Janeiro: Fundação Getúlio Vargas, 1998.

PRADO, Décio de Almeida. O teatro brasileiro moderno. São Paulo: Perspectiva, 2001.

. "A personagem no teatro". In: CANDIDO, Antonio (org.). A personagem de ficção. São Paulo: Perspectiva, 1976.

VELHO, Gilberto. "O estudo do comportamento desviante: a contribuição da antropologia social". In: Velho, Gilberto (org.). Desvio e divergência: uma crítica da patologia social. Zahar, Rio de Janeiro: 1985. 